\title{
Article \\ Persistent Postural-Perceptual Dizziness Interventions-An Embodied Insight on the Use Virtual Reality for Technologists
}

\author{
Syed Fawad M. Zaidi ${ }^{1, *}$, Niusha Shafiabady ${ }^{2}$ and Justin Beilby ${ }^{3}$ \\ 1 Business and Information Systems, Torrens University Australia, Sydney 2000, Australia \\ 2 Creative Technology, Torrens University Australia, Sydney 2000, Australia; admin@niushashafiabady.com \\ 3 Academic Research, Torrens University Australia, Adelaide 5000, Australia; jbeilby@torrens.edu.au \\ * Correspondence: fawad.zaidi@torrens.edu.au
}

\section{check for}

updates

Citation: Zaidi, S.F.M.; Shafiabady,

\section{N.; Beilby, J. Persistent}

Postural-Perceptual Dizziness

Interventions-An Embodied Insight

on the Use Virtual Reality for

Technologists . Electronics 2022, 11,

142. https://doi.org/10.3390/

electronics11010142

Academic Editors: Soon Ki Jung,

Byung Cheol Song and Juan M.

Corchado

Received: 13 October 2021

Accepted: 24 December 2021

Published: 3 January 2022

Publisher's Note: MDPI stays neutral with regard to jurisdictional claims in published maps and institutional affiliations.

Copyright: () 2022 by the authors. Licensee MDPI, Basel, Switzerland. This article is an open access article distributed under the terms and conditions of the Creative Commons Attribution (CC BY) license (https:// creativecommons.org/licenses/by/ $4.0 /)$.

\begin{abstract}
Persistent and inconsistent unsteadiness with nonvertiginous dizziness (persistent posturalperceptual dizziness (PPPD)) could negatively impact quality of life. This study highlights that the use of virtual reality (VR) systems offers bimodal benefits to PPPD, such as understanding symptoms and providing a basis for treatment. The aim is to develop an understanding of PPPD and its interventions, including current trends of VR involvement to extrapolate and re-evaluate VR design strategies. Therefore, recent virtual-reality-based research work that progressed in understanding PPPD is identified, collected, and analysed. This study proposes a novel approach to the understanding of PPPD, specifically for VR technologists, and examines the principles of effectively aligning VR development for PPPD interventions.
\end{abstract}

Keywords: persistent postural-perceptual dizziness; protocol; virtual reality

\section{Introduction}

Before persistent postural-perceptual dizziness (PPPD) was classified as a disorder, scientists had investigated the related dizziness symptoms, their factors, triggers, and treatments, which were related to vestibular dysfunction and balance problems. It all started with the discovery of phobic postural vertigo (PPV) in 1986 [1]. Symptoms were reported by oscillating unsteadiness and nonvertiginous postural dizziness, which were triggered by exposure to crowded external environments. Further research found that PPV was a neurological condition with behavioural attributes such as anxiety and mild depression, and ruled it out as a psychiatric disorder. PPV was later categorised as chronic subjective dizziness (CSD) in the 2000s [2]. Later, space-motion discomfort (SMD) symptoms were identified as overlapping factors with PPV and CSD [3]. In 2010, scientists globally started conducting investigations in collecting the core features of the above disorders along with visual vertigo $[4,5]$. Moreover, the Barany Society reached a consensus that PPPD includes core features described in the above-mentioned syndromes, including postural sensitivity. In 2017, the World Health Organization included PPPD in the list of diagnoses in the International Classification of Diseases (ICD-11) [5,6]. PPPD is a described as dizziness, nonspinning vertigo, and/or unsteadiness that persist for 3 months or more due to a mismatch in sensory stimuli triggered by active or passive motion, complex visual and active or passive motions [7-9]. To understand whether one is suffering with PPPD, the Barany Society criteria must be met (see Table 1).

This study underlines the embodiment of improved and robust VR design principles for PPPD assessments and treatments. With the conducted investigation and highlighted areas of focus, VR technologists could identify gaps and advise better on VR-based design and development strategies for exposure therapy, which would sync well with the requirements entailed by therapists (Figure 1). 
Table 1. Criteria for diagnosis of persistent postural-perceptual dizziness $[6,8]$.

\begin{tabular}{ll}
\hline 1 & Symptom(s) of (nonvertiginous) dizziness, and sensation of swaying or nonspinning \\
vertigo for 3 months or more. \\
Presence of persistent dizziness symptoms that could be aggravated by (1) upright \\
postural position, passive and active motion with respect to surroundings; \\
(2) continuous exposure to complex static or dynamic visual patterns or stimuli. \\
Disorder starts shortly after an event that causes acute vestibular symptoms or \\
balance problems, neurological or medical illness, and psychological distress (which \\
is rare), and develops slowly.
\end{tabular}

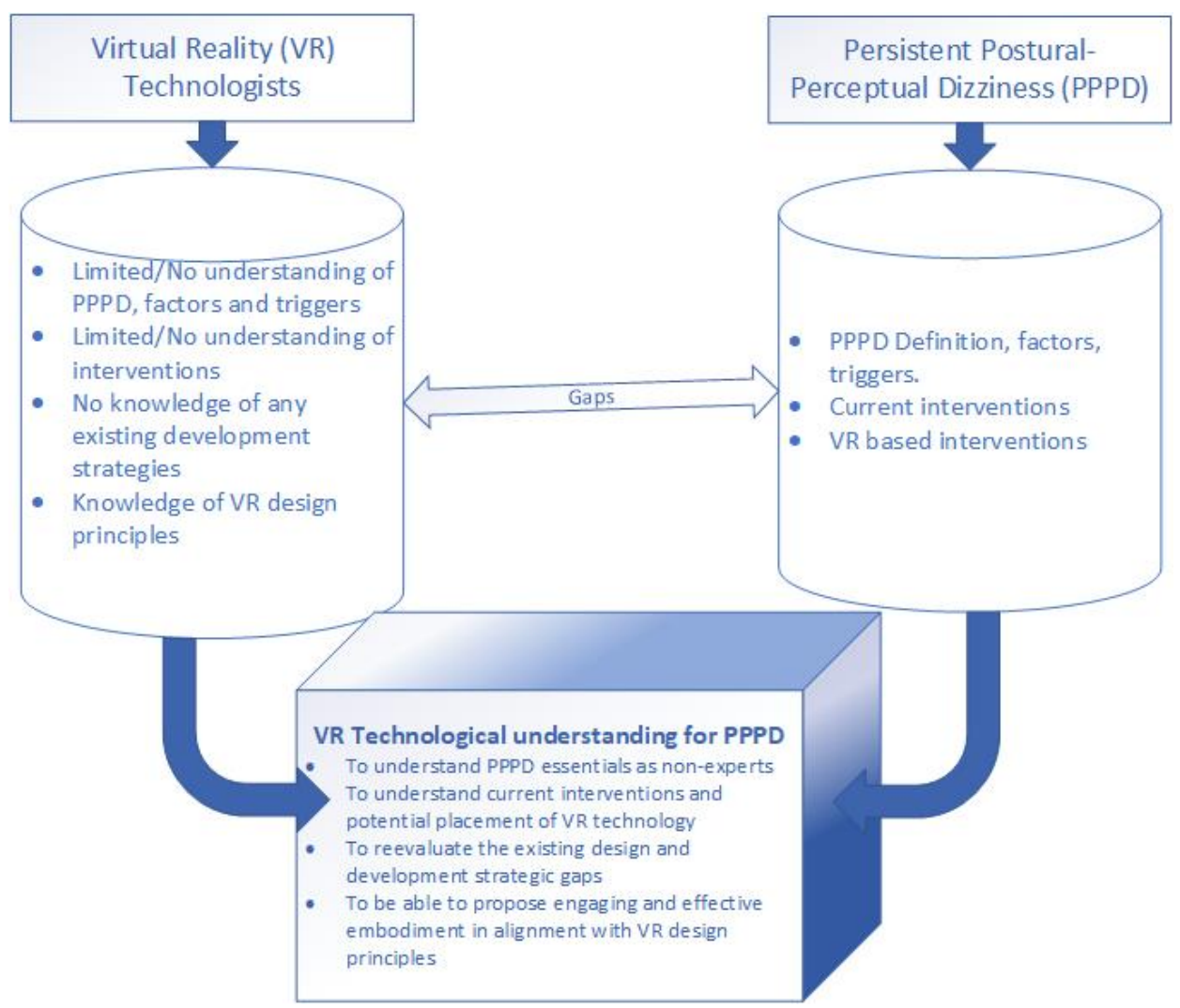

Figure 1. Bridging knowledge gaps of PPPD for VR technologists.

\section{Understanding Existing Interventions as VR Technologists}

PPPD is a recent classification with limited research conducted on the efficacy of conventional vestibular rehabilitation approaches. Therapeutic approaches need to understand and treat PPPD while considering the core principles. The steps would be the accurate diagnosis of symptoms of PPPD, followed by clinical advice for medication, healthy dietary habits, psychotherapy, and vestibular rehabilitation therapy.

To understand how VR technologists could improve or introduce strategies that continue to benefit PPPD patients in improving their symptoms, we cover the important findings of various therapies. The summaries below highlight the effects of each therapy including numbers of participants involved in each study as a benchmark for future research experiments.

\subsection{Medication for Functional Dizziness and Possible VR Development Direction}

It is important for VR technologists to be aware of the role of medication as therapy for functional dizziness. The details here would pave way to cautious decision making for creating a suitable VR environment in consultation with therapists that could support the importance of having medication and/or exposure in the real-world simulated environment. Research studies showed that most chronic subjective dizziness patients have felt a 
reduction in dizziness and unsteadiness by taking selective serotonin reuptake inhibitors (SSRI) and serotonin-norepinephrine reuptake inhibitors (SNRI) [10]. Subjective chronic dizziness is one of the main predecessors of PPPD. Patients are treated with the two antidepressant medications above in open-label clinical trials supported by multiple perspectives. There were no randomised clinical trials in this research. One study investigated SSRI medication efficacy on patients with dizziness irrespective of having neurotologic illness. Patients were diagnosed with major or major or minor psychiatric disorders $(n=40)$ [11].

No significant difference was observed in the response between patients with fewer and those with major psychiatric symptoms. Along with patients with psychiatric disorder, patients with coexisting peripheral vestibular problems or migraine issues improved more than patients with a deficit central nervous system did. In another study on the longitudinal pattern of patients' symptoms and the efficacy of SSRI treatment, 88 patients were treated with SSRIs between 1998 and 2003 [2]. They entered SSRI treatment after extensive detailed neurologic and psychiatric assessments, which revealed symptoms of chronic subjective dizziness (CSD) with accompanying anxiety. They observed that patients with notable anxiety prior to neurologic illness might need more thorough treatment compared to patients with primary neurologic conditions and continuous anxiety disorders or patients with only anxiety issues. Therefore, patients with significant anxiety predating neurological issues may require comparatively more intensive therapy [12]. It would be a vital for VR technologists to seek how and what sort of VR environment could further facilitate effective medication therapy.

\subsection{Cognitive-Behavioural Therapies for Functional Dizziness and Possible VR Development Direction}

VR exposure has the ability to create environments that could immerse a user in a world of their choice. With artificial intelligence (AI) systems such as chatbots and avatars, VR development has taken immersion to the next level, where users connected well with the virtual character [13-15]. This section provides VR technologists with the necessary background research of CBT on functional dizziness, including the number of participants involved in the experiments. There is very limited research in cognitivebehavioural studies for treating functional dizziness. Holmberg et al. studied how effective CBT is by adding the therapy to self-administrated vestibular rehabilitation for patients with PPV [16]. Patients $(n=39)$ showed some short-term improvement in symptoms. In the 1-year follow-up study $(n=20)$, these improvements were not sustained. Later, a study focused on cognitive-behavioural therapy (CBT) involving 41 patients with CSD [17]. They were categorised in either a waiting-list group $(n=21)$ or a treatment group $(n=20)$. Treatment was given during three weekly sessions. With just three sessions of psychological intervention, dizziness-related symptoms were significantly reduced. Another follow-up study conducted research on thee long-term benefits of CBT, and concluded that the therapy resulted in improvement between 1 to 6 months [18]. A pilot study also showed that patients had experienced normalisation in their postural behaviour [19]. Although there is limited direct evidence of improvement, patients may receive help with noticeable fear of dizziness or falling by going through CBT [20]. Moreover, clinical experience recently backed reports suggesting the use of variety of interventions including CBT, medication, and vestibular rehabilitation, depending on the patient's need and treatment preferences. We see potential for bringing virtual avatars or chatbots into cognitive-behavioural therapies (CBT) along with interactivity with different levels of immersion.

\subsection{Vestibular Rehabilitation Therapies for Functional Dizziness and Possible VR Development Direction}

Researchers found significant improvements with immersion and interactive virtual environments that could replace conventional vestibule therapy regarding self-report and performance measures [21-23]. Evidence existed that supported the effectiveness of vestibular rehabilitation for a variety of vestibular conditions, and suggested further research for long-term improvement [24]. The therapy addresses key issues of functional dizziness 
patients by (1) enhancing gaze stability, (2) enhancing postural stability, (3) improving vertigo, and (4) improving activities of daily living [25]. This therapy facilitates vestibular recovery mechanisms, including vestibular adaptation, substitution, and habituation. The consulting neurologist recommends appropriate therapy tailored to the needs of patients with PPPD. Moreover, studies showed that vestibular therapy promoting habituation is most appropriate for patients with PPPD [26,27]. A study on the efficacy of vestibular rehabilitation, specifically for PPPD patients, was conducted in 2014 and concluded that vestibular rehabilitation reduces the severity of vestibular symptoms by around $60 \%$ to $80 \%$. To understand the habituation forms of VBRT, research was conducted including a retrospective chart review and phone survey of 26 patients over 27.5 months after receiving details about PPPD and direction for home-based vestibular rehabilitation programs [28]. Results showed that a vestibular habituation exercise programme was helpful for the majority of PPPD patients. The study was the important first step in determining the effectiveness of using habituation exercises for treating individuals with PPPD. It also concluded that there is a long-term clinical benefit of the techniques for PPPD patients, including exhausting abnormal reflexive responses to motion and reducing patients' sensitivity towards visual stimuli. Pavlou et al. conducted a randomised trial study where 60 participants with chronic peripheral vestibular symptoms were divided into treatment groups for OptoKinetic stimuli (OK) training, namely, full-field visual environment rotation (group OKF, $\mathrm{n}=20$ ), supervised (group OKS, $\mathrm{n}=20$ ), or unsupervised (group OKU, $\mathrm{n}=$ 20) [29]. Participants had weekly sessions and were advised customised home exercises using the DVD provided during the experiment. No significant group differences were found at either the baseline or postinterventions. All groups showed significant withingroup improvements for vestibular (i.e., light-headedness), visual vertigo, and autonomic symptoms. Vestibular rehabilitation in combination with cognitive-behavioural therapy (CBT) significantly improved dizziness symptoms in a small group of patients [21,30,31]. A one-year follow-up trial determined that positive effects are transient [32]. Another, study suggested that a combined treatment using CBT, vestibular rehabilitation, psychoeducation, and antidepressants may alleviate dysfunctional illness behaviour and dizziness, which was addressed in recent interventions [33]. A combination of treatments also improved postural strategy and dizziness [19]. These above therapies show that VR could create customised individualised environment therapies depending on the requirement, whether it is about physical activities, CBT, medication, or combination of therapies. VR immersion could give an ultimate experience if VR technologists focus on developing relevant strategies after understanding the main issue. At this stage, after having the core understanding of therapies in the absence of VR, VR technology could facilitate appropriate individualised interventions through better-developed strategies. In the next section, we highlight how VR technology has probed vestibular rehabilitation including studying PPPD. With research in functional dizziness using VR, researchers focused on potential applications of VR in improving PPPD symptoms.

\subsection{Virtual Reality as Vestibular Rehabilitation for Improvement of Functional Dizziness}

Due to variation in responses to therapy, there are only limited research outcomes to support vestibular rehabilitation's positive effect on symptom recovery and functional improvement [34]. A few studies showed that patients given exposure to optokinetic stimulation resulted in decreased dependence on visual input for perceptual and postural responses $[35,36]$. One study showed that short-term adaptive changes to visiovestibular therapy prompted adaptive changes, improving visual dependency in healthy participants [36]. There was significant improvement in patients' visual vertigo (another form of functional dizziness that slightly overlaps with PPPD) symptoms when simulator-based optokinetic exposure was given with whole-body or visual environment rotators in combination with customised vestibular exercise regime [37]. Studies showed mediocre predictable patients' adaptation to time consumption, repetition, and monotonous procedure [21,38]. Therefore, more efficient and cost-effective types of virtual-reality-based treatments were 
proposed as potential alternative [21]. A virtual-reality-based pilot study was conducted on visual vertigo, a symptom that overlapped to some extent with PPPD [39]. Exposure to dynamic virtual-reality environments should be considered to be a useful adjunct to vestibular rehabilitation programs for patients with peripheral vestibular and visual vertigo symptoms. Second, similar to virtual reality, games can be an appealing area of research for augmented therapy because using vestibular rehabilitation-relevant movements in the context of an engaging and motivational game could improve the result from the therapy. Thus, integrating video games may provide a solution for retaining participant numbers, and augmented engagement and accessibility in the vestibular rehabilitation. The videogame industry produces accessible and affordable activities that engage users for long periods. In spite of many techniques available, including virtual reality, engagement and accessibility are major obstacles to participants in achieving necessary treatment and for the appropriate duration. Studies provided preliminary descriptions of the benefits of commercially available video games in rehabilitation, and showed that interactive exercise linked with games can significantly improve players' visual-spatial perception and visual tracking skills [40-42]. Recently, virtual reality has been a part of vestibular rehabilitation for several studies, but to date, only one (randomised control pilot) study has been conducted that implemented vestibular rehabilitation procedures with head-mounted display (HMD)-based protocols to understand the effect in unilateral vestibular hypofunction [43]. In that study, the HMD group showed overall improvement in vestibular-ocular reflex gain on the lesional side, in posturography parameters in the low-frequency spectrum. The main advantage of introducing HMD for virtualo-reality environments is their proximity to the eye that offers images at high resolution [44] and can follow the user's movements, making them feel like a part of environment generated by the computer [45]. Patients going through interactive virtual reality (using HMD)-based gamified (bringing engagement; accessibility) intervention are likely to be involved in the intervention improving their PPPD symptoms. The section below introduces the recent research of VR in PPPD, the directions it has taken, and gaps that need to be addressed.

\section{Persistent Postural-Perceptual Dizziness and Virtual Reality}

Virtual-reality technology is seen as the major technological tool that could benefit vestibular rehabilitation [21]. Technology using head-mounted devices (HMD) is yet to take advantage of giving near real-world environment simulations for people with PPPD. As VR technologists, we could see the opportunity of understanding PPPD and dizziness is not a new issue that VR developers have encountered. Recent research shows a major breakthrough in understanding cybersickness and the process to alleviate it $[46,47]$. Understanding cybersickness could benefit technologists to contribute towards PPPD treatment intervention. Therefore, it is important that VR technologists understand PPPDand VR-based contributions so far in this area.

\section{Trends of VR-Based Research on PPPD}

There are limited VR-based research outcomes for PPPD, and their findings still require further investigation, as PPPD is relevantly new to the Classification of Vestibular Disorders of the Bárány Society [48]. For the purpose of focused reading on current progress of VR for PPPD, the inclusion criteria for data analysis are based on four categories in relation to VR, namely, year of study, participants, outcome, and conclusion.

\section{Data Collection and Analysis}

We chose articles through rigorous database search and collated the essential findings. Articles were selected from electronic databases Cochrane Library PubMed (including MEDLINE; Ovid), EBSCOhost (CINAHL—Cumulative Index to Nursing and Allied Health Literature), Scopus (Elsevier), and PubMed (including MEDLINE; Ovid) Cochrane Library. Although limited research was conducted in PPPD using VR, findings show promising potential of using the VR technology. Researchers endeavoured to further understand 
the dynamic balance, activities of vestibular and visual cortices, and brain responses to visual cues in simulated environment. The studies clearly investigated issues involved with PPPD disorder and how they would pathophysiologcally affect the people. The authors cautiously reached conclusions for the general population because of the inclusion criteria and the sample size considered in each research experiment (Table 2). It is still not clear from existing research how the development of VR environment is impacted by patients' self-motivation and engagement. The positive aspects of VR, including real-world exposure, real-time flexibility of changing complex level of exposure, and the adaptability to the hybrid approach of the therapies are either limited or not discussed. In the next section, we discuss how these gaps, if addressed in future research and considered in therapy strategies, could positively impact patients' lives.

Table 2. Current trends of virtual-reality engagement for PPPD.

\begin{tabular}{|c|c|}
\hline Author(s): & Riccelli et al. [49] \\
\hline Year: & 2017 \\
\hline Study: & $\begin{array}{l}\text { To determine the areas of the brain that are linked with increased visual motion } \\
\text { stimulus sensitivity representing roller-coaster rides in people with PPPD. }\end{array}$ \\
\hline Participants: & $\begin{array}{l}15 \text { people with PPPD and } 15 \text { healthy controls including demographics, state and } \\
\text { trait anxiety, and motion sickness vulnerability. }\end{array}$ \\
\hline Outcome: & $\begin{array}{l}\text { Contrary to increased middle insular response found in healthy controls, no } \\
\text { difference in middle insular activity was seen in people with PPPD }\end{array}$ \\
\hline Conclusion & $\begin{array}{l}\text { In people with PPPD, lack of medial insular activation causes disruption of spatial } \\
\text { motion encoding and there is is greater reliance on visual cues as noted with increase } \\
\text { activation of the visual cortex with increased severity of PPPD. }\end{array}$ \\
\hline Author(s): & Passamonti et al. [50] \\
\hline Year: & 2018 \\
\hline Study: & $\begin{array}{l}\text { To determine if neuroticism and introversion have differential effects on } \\
\text { visuovestibular system function in people having PPPD and healthy controls }\end{array}$ \\
\hline Participants: & $\begin{array}{l}15 \text { people with PPPD and } 15 \text { demographic and motion-sickness susceptibility } \\
\text { matched healthy controls. }\end{array}$ \\
\hline Conclusion & $\begin{array}{l}\text { There is a positive correlation between neuroticism and inferior frontal gyrus (IFg) } \\
\text { activity in people with PPPD. In addition, neuroticism increased the connection } \\
\text { between IFg and occipital areas during vertical motion in patients with PPPD. } \\
\text { In people with PPPD, presence of neuroticism is associated with enhanced activation } \\
\text { and connectivity between the brain areas responsible attention and vision. This } \\
\text { occurred during vertical movement. }\end{array}$ \\
\hline Author(s): & Aharoni et al. [51] \\
\hline Year: & 2019 \\
\hline Study: & $\begin{array}{l}\text { To assess the feasibility of a novel virtual-reality-based four-square step square test } \\
\text { (FSST-VR) for measuring dynamic balance in people with PPPD }\end{array}$ \\
\hline Participants: & 3 people with PPPD and 8 healthy controls \\
\hline Outcome: & $\begin{array}{l}\text { FSST-VR is a feasible method to assess dynamic balance within complex visual } \\
\text { environment in people with PPPD. Preliminary descriptive analysis of the data } \\
\text { shows that people with PPPD take shorter and less smooth steps in anteroposterior } \\
\text { direction. }\end{array}$ \\
\hline Conclusion & $\begin{array}{l}\text { FSST-VR may be a feasible paradigm to assess dynamic balance in people with } \\
\text { PPPD symptoms and gives additional information about spatiotemporal measures } \\
\text { which may help differentiate between healthy and people with PPPD. }\end{array}$ \\
\hline Author(s): & Breinbauer et al. [52] \\
\hline Year: & 2020 \\
\hline Study: & $\begin{array}{l}\text { To investigate if people with PPPD perform poorer in virtual spatial navigational } \\
\text { task as compared to healthy individuals and people with other vestibular conditions. }\end{array}$ \\
\hline Participants: & $\begin{array}{l}19 \text { people with PPPD, } 19 \text { people with other vestibular disorders, and } 18 \text { healthy } \\
\text { controls. }\end{array}$ \\
\hline Outcome: & $\begin{array}{l}\text { As compared to the healthy individuals and people with other vestibular conditions, } \\
\text { people with PPPD performed the navigationally demanding task (when the target is } \\
\text { invisible) more chaotically, and utilized poorly organised search strategies with } \\
\text { greater diversity in the navigational pool. }\end{array}$ \\
\hline Conclusion & $\begin{array}{l}\text { Poor spatial navigation performance in people in PPPD may be useful in } \\
\text { differentiating PPPD from non-PPPD patients. }\end{array}$ \\
\hline
\end{tabular}


Table 2. Cont.

\begin{tabular}{ll}
\hline Author(s): & Aharoni et al. [53] \\
Year: & 2021 \\
& To study and evaluate dynamic balance performance including assessing of \\
study: & $\begin{array}{l}\text { spatiotemporal kinematics, sel-reported outcomes, and functional mobility tests as } \\
\text { compared to healthy individuals using four-square step square in VR }\end{array}$ \\
& 23 people with PPPD and 29 healthy controls. \\
Participants: & As compared to healthy individuals, people with PPPD were able to show subtle \\
& alterations in task performance. However, PPPD individuals found the tasks \\
Challenging at times and responded with postural sways. \\
high visual load contrast relationship found between self-reported and functional \\
motion characteristics using FSST task. However, the task was feasible for people \\
with PPPD, as overall performance was similar to controls. Detailed investigation of \\
dynamic balance is suggested.
\end{tabular}

\section{Discussion}

Virtual-reality technology is common among consumers. People are aware of VR technologies' capabilities and considerations of side effects of using VR gadgets. VR development in health sciences is seen as an effective tool to support treatments and diagnosis (Figure 2) [54-56]. To serve the purpose of understanding PPPD, we kept the discussion specific to the technical terms used by virtual-reality developers.

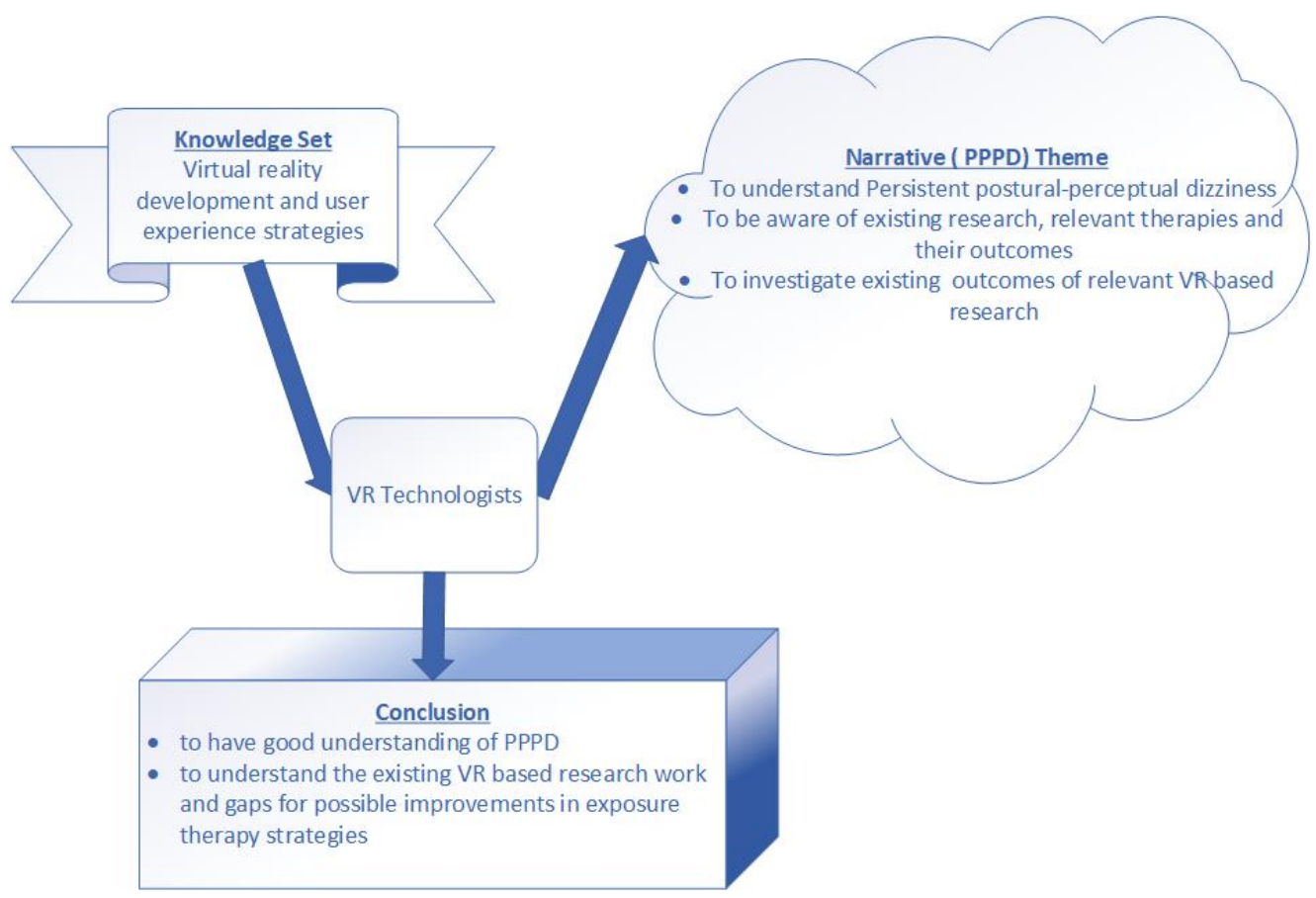

Figure 2. Narrative theme map.

\subsection{Virtual-Reality-Flexible Environment for Different Symptom Levels}

Virtual-reality exposure therapy could highlight how neuroticism could positively correlate and increase neural network activities, bringing them into experiencing rollercoaster rides without actually putting them in a real environment [50]. This shows that virtual reality could expose patients to near-real environments and study how motion sickness or PPPD actually affects persons with symptoms. To further adjust the engagement of immersion for PPPD patients, exposure could vary from easy to advanced levels of complexity in the immersive experience. Variance in the levels of exposure of similar environments is always engaging to a wider pool of users [57]. Virtual-reality developers could actually indulge in understanding how the different levels of simulated environments are effective for PPPD patients going through exposure therapy. 


\subsection{Virtual-Reality Environment-Enhancement to Conventional Tools}

Virtual reality is not new to the health sciences, as the technology is capable of replacing the real world with simulated environments, creating unique experiences that could increase engagement for end users [58]. A recent study on FSST-VR showed that the technology is able to provide additional information about the PPPD patients on spatial and temporal parameters when compared with healthy participants. VR did not exacerbate the symptoms of PPPD, as further studies were ongoing to understand dynamic balance [51]. Therefore, virtual reality could be used along with other therapies for diagnosis and/or treatment purposes. Understanding the diagnostic criteria of PPPD and managing them with effective communication and tailored treatment strategies [9] is crucial. In addition, there is a way for VR developers to work along with PPPD experts to develop an effective tool to address symptoms [59].

\subsection{Virtual-Reality Environment-Extensive Variety of Exposure for Engagement and Interactivity Purpose Using Design Thinking Approach}

The choice of virtual-world exposure (simulation of the real world) and its suitability with respect to the diagnosis and treatment purpose at individual level is important. Therefore, an appropriate engaging VR-based system as a stand-alone system or combined with other methods, is required. Different VR environments were found useful for the diagnosis purposes including impairments in spatial navigation, vestibular and visual cortices [49,52].

Although we have seen recent developments of using VR in PPPD, it is still not clear how patients could be convinced to voluntarily use VR with thee right exposure therapy that could not only help the diagnosis of the symptoms, but also support treatment. Strategies needs to be in place to support VR developers in understanding the core of the symptoms, and health experts in understanding the VR technology. User-centred design is one way to see through the lens of users by using design thinking concepts [60]. Hence, VR-based interventions could be the appropriate tools in the long run as they have the capacity to be tuned to the properties of engagement, interactivity, and adjustability of environments as per users' needs [61,62].

\subsection{Virtual-Reality Development-Electronic-Equipment Advancement}

The choice of VR environment and VR planning would not be effective if VR technology does not keep up with the new advancements of available hardware. There is limited information on hardware specifications for VR development in recent studies [63]. The dominant market of Oculus and HTC has seen a major revolution in their achievement in addressing issues with previous models and improving to the level where the technology could cater to all types of users [64]. PPPD patients can use typical VR headsets to take advantage of the latest systems for VR exposure. The specification details for the VR development and execution show that the hardware market and VR gadgets are catching up from a compatibility perspective. Recent graphics cards [65] and high-capacity memory units have facilitated effortless exposure experience [66]. With the emerging advancement of VR in the health sector, VR development takes advantage of hardware compatibility to create conducive environments for PPPD patients.

\section{Conclusions}

This study outlined recent PPPD interventions through the lens of VR technologists. Screening was conducted on current trends in VR research to identify and reduce PPPD symptoms. It is important to harvest the long-term positive effects of VR technology to help PPPD patients through VR immersion. The direction of possible consideration is backed up by the established strengths of the technology: (1) flexibility in complexity levels of immersive environment, (2) ability to blend with other intervention tools, and (3) variety in environmental exposure. Further research can be conducted on a wider audience that struggles to enjoy commercial VR products to explore the ways that provide 
entertaining and engaging immersive experiences. Additionally, it is important to carry on experiments on larger populations, where the idea of utilising VR to assist people with PPPD seems feasible and functional for the purposes of entertainment, engagement, treatment, and habituation.

Author Contributions: Conceptualization, S.F.M.Z.; methodology, S.F.M.Z.; software, S.F.M.Z.; validation, S.F.M.Z. and N.S.; formal analysis, S.F.M.Z.; investigation, S.F.M.Z.; resources, S.F.M.Z.; data curation,S.F.M.Z. and N.S.; writing-original draft preparation, S.F.M.Z.; writing-review and editing, S.F.M.Z., N.S. and J.B.; visualization, S.F.M.Z.; supervision, N.S. and J.B.; project administration, S.F.M.Z., N.S. and J.B. All authors have read and agreed to the published version of the manuscript.

Funding: This research received no external funding.

Conflicts of Interest: The authors declare no conflict of interest.

\section{References}

1. Brandt, T.; Dieterich, M. Phobic postural vertigo attacks-a new syndrome. Munch. Med. Wochenschr. 1986, 128, 247-250.

2. Staab, J.P.; Ruckenstein, M.J. Chronic dizziness and anxiety: Effect of course of illness on treatment outcome. Arch. Otolaryngol.Head Neck Surg. 2005, 131, 675-679. [CrossRef]

3. Jacob, R.G.; Redfern, M.S.; Furman, J.M. Space and motion discomfort and abnormal balance control in patients with anxiety disorders. J. Neurol. Neurosurg. Psychiatry 2009, 80, 74-78. [CrossRef] [PubMed]

4. Bronstein, A.M. Vision and vertigo. J. Neurol. 2004, 251, 381-387. [CrossRef]

5. Dieterich, M.; Staab, J.P. Functional dizziness: From phobic postural vertigo and chronic subjective dizziness to persistent postural-perceptual dizziness. Curr. Opin. Neurol. 2017, 30, 107-113. [CrossRef]

6. Staab, J.P.; Eckhardt-Henn, A.; Horii, A.; Jacob, R.; Strupp, M.; Brandt, T.; Bronstein, A. Diagnostic criteria for persistent postural-perceptual dizziness (PPPD): Consensus document of the committee for the Classification of Vestibular Disorders of the Bárány Society. J. Vestib. Res. 2017, 27, 191-208. [CrossRef] [PubMed]

7. Holle, D.; Schulte-Steinberg, B.; Wurthmann, S.; Naegel, S.; Ayzenberg, I.; Diener, H.C.; Katsarava, Z.; Obermann, M. Persistent postural-perceptual dizziness: A matter of higher, central dysfunction? PLoS ONE 2015, 10, e0142468. [CrossRef]

8. Staab, J.P. Persistent Postural-Perceptual Dizziness. In Seminars in Neurology; Thieme Medical Publishers: New York, NY, USA, 2020.

9. Popkirov, S.; Staab, J.P.; Stone, J. Persistent postural-perceptual dizziness (PPPD): A common, characteristic and treatable cause of chronic dizziness. Pract. Neurol. 2018, 18, 5-13. [CrossRef] [PubMed]

10. Staab, J.P. Chronic subjective dizziness. Contin. Lifelong Learn. Neurol. 2012, 18, 1118-1141. [CrossRef]

11. Staab, J.P.; Ruckenstein, M.J.; Solomon, D.; Shepard, N.T. Serotonin reuptake inhibitors for dizziness with psychiatric symptoms. Arch. Otolaryngol.-Head Neck Surg. 2002, 128, 554-560. [CrossRef]

12. Popkirov, S.; Stone, J.; Holle-Lee, D. Treatment of persistent postural-perceptual dizziness (PPPD) and related disorders. Curr. Treat. Options Neurol. 2018, 20, 50. [CrossRef]

13. Butt, A.H.; Ahmad, H.; Goraya, M.A.; Akram, M.S.; Shafique, M.N. Let's play: Me and my AI-powered avatar as one team. Psychol. Mark. 2021, 38, 1014-1025. [CrossRef]

14. Lalwani, T.; Bhalotia, S.; Pal, A.; Rathod, V.; Bisen, S. Implementation of a Chatbot System using AI and NLP. Int. J. Innov. Res. Comput. Sci. Technol. (IJIRCST) 2018, 6. http://dx.doi.org/10.2139/ssrn.3531782. [CrossRef]

15. Do, H.J.; Fu, W.T. Empathic virual assistant for healthcare information with positive emotional experience. In Proceedings of the 2016 IEEE International Conference on Healthcare Informatics (ICHI), Chicago, IL, USA, 4-7 October 2016; p. 318.

16. Holmberg, J.; Karlberg, M.; Harlacher, U.; Rivano-Fischer, M.; Magnusson, M. Treatment of phobic postural vertigo. J. Neurol. 2006, 253, 500-506. [CrossRef] [PubMed]

17. Edelman, S.; Mahoney, A.E.; Cremer, P.D. Cognitive behavior therapy for chronic subjective dizziness: A randomized, controlled trial. Am. J. Otolaryngol. 2012, 33, 395-401. [CrossRef]

18. Mahoney, A.E.; Edelman, S.; Cremer, P.D. Cognitive behavior therapy for chronic subjective dizziness: Longer-term gains and predictors of disability. Am. J. Otolaryngol. 2013, 34, 115-120. [CrossRef]

19. Best, C.; Tschan, R.; Stieber, N.; Beutel, M.E.; Eckhardt-Henn, A.; Dieterich, M. STEADFAST: Psychotherapeutic intervention improves postural strategy of somatoform vertigo and dizziness. Behav. Neurol. 2015, 2015, 456850. [CrossRef] [PubMed]

20. Whalley, M.G.; Cane, D.A. A cognitive-behavioral model of persistent postural-perceptual dizziness. Cogn. Behav. Pract. 2017, 24, 72-89. [CrossRef]

21. Bergeron, M.; Lortie, C.L.; Guitton, M.J. Use of virtual reality tools for vestibular disorders rehabilitation: A comprehensive analysis. Adv. Med. 2015, 2015, 916735. [CrossRef] [PubMed]

22. Alahmari, K.A.; Sparto, P.J.; Marchetti, G.F.; Redfern, M.S.; Furman, J.M.; Whitney, S.L. Comparison of virtual reality based therapy with customized vestibular physical therapy for the treatment of vestibular disorders. IEEE Trans. Neural Syst. Rehabil. Eng. 2013, 22, 389-399. [CrossRef]

23. Song, J.J. Virtual reality for vestibular rehabilitation. Clin. Exp. Otorhinolaryngol. 2019, 12, 329. [CrossRef] [PubMed] 
24. Horak, F.; Jones-Rycewicz, C.; Black, F.O.; Shumway-Cook, A. Effects of vestibular rehabilitation on dizziness and imbalance. Otolaryngol.-Head Neck Surg. 1992, 106, 175-180. [CrossRef]

25. Han, B.I.; Song, H.S.; Kim, J.S. Vestibular rehabilitation therapy: Review of indications, mechanisms, and key exercises. J. Clin. Neurol. 2011, 7, 184-196. [CrossRef]

26. Whitney, S.; Alghwiri, A.; Alghadir, A. An overview of vestibular rehabilitation. Handb. Clin. Neurol. 2016, 137, 187-205.

27. Staab, J.P. Behavioral aspects of vestibular rehabilitation. NeuroRehabilitation 2011, 29, 179-183. [CrossRef]

28. Thompson, K.J.; Goetting, J.C.; Staab, J.P.; Shepard, N.T. Retrospective review and telephone follow-up to evaluate a physical therapy protocol for treating persistent postural-perceptual dizziness: A pilot study. J. Vestib. Res. 2015, 25, 97-104. [PubMed]

29. Pavlou, M.; Bronstein, A.M.; Davies, R.A. Randomized trial of supervised versus unsupervised optokinetic exercise in persons with peripheral vestibular disorders. Neurorehabilit. Neural Repair 2013, 27, 208-218. [CrossRef] [PubMed]

30. Bamiou, D.; Luxon, L. Vertigo-Clinical Management and Rehabilitation. In Scott-Brown's Otorhinolaryngology, Head and Neck Surgery 7th. CRC Press: New York, NY, USA; 2008. pp. 3791-3817

31. Norre, M.; De Weerdt, W. Treatment of vertigo based on habituation: 2. Technique and results of habituation training. J. Laryngol. Otol. 1980, 94, 971-977. [CrossRef]

32. Holmberg, J.; Karlberg, M.; Harlacher, U.; Magnusson, M. One-year follow-up of cognitive behavioral therapy for phobic postural vertigo. J. Neurol. 2007, 254, 1189. [CrossRef]

33. Tschan, R.; Eckhardt-Henn, A.; Scheurich, V.; Best, C.; Dieterich, M.; Beutel, M. Steadfast-effectiveness of a cognitive-behavioral self-management program for patients with somatoform vertigo and dizziness. Psychother. Psychosom. Med. Psychol. 2012, $62,111-119$.

34. McDonnell, M.; Hillier, S.; Vestibular rehabilitation for unilateral peripheral vestibular dysfunction. Cochrane Database Syst. Rev. 2015. [CrossRef] [PubMed]

35. Guerraz, M.; Yardley, L.; Bertholon, P.; Pollak, L.; Rudge, P.; Gresty, M.; Bronstein, A.M. Visual vertigo: Symptom assessment, spatial orientation and postural control. Brain 2001, 124, 1646-1656. [CrossRef]

36. Pavlou, M.; Quinn, C.; Murray, K.; Spyridakou, C.; Faldon, M.; Bronstein, A.M. The effect of repeated visual motion stimuli on visual dependence and postural control in normal subjects. Gait Posture 2011, 33, 113-118. [CrossRef] [PubMed]

37. Pavlou, M.; Lingeswaran, A.; Davies, R.A.; Gresty, M.A.; Bronstein, A.M. Simulator based rehabilitation in refractory dizziness. J. Neurol. 2004, 251, 983-995. [CrossRef]

38. Hsu, S.Y.; Fang, T.Y.; Yeh, S.C.; Su, M.C.; Wang, P.C.; Wang, V.Y. Three-dimensional, virtual reality vestibular rehabilitation for chronic imbalance problem caused by Meniere's disease: A pilot study. Disabil. Rehabil. 2017, 39, 1601-1606. [CrossRef] [PubMed]

39. Pavlou, M.; Kanegaonkar, R.; Swapp, D.; Bamiou, D.; Slater, M.; Luxon, L. The effect of virtual reality on visual vertigo symptoms in patients with peripheral vestibular dysfunction: A pilot study. J. Vestib. Res. 2012, 22, 273-281. [CrossRef]

40. Agmon, M.; Perry, C.K.; Phelan, E.; Demiris, G.; Nguyen, H.Q. A pilot study of Wii Fit exergames to improve balance in older adults. J. Geriatr. Phys. Ther. 2011, 34, 161-167. [CrossRef]

41. Achtman, R.L.; Green, C.S.; Bavelier, D. Video games as a tool to train visual skills. Restor. Neurol. Neurosci. 2008, 26, 435-446.

42. Ricci, N.A.; Aratani, M.C.; Doná, F.; Macedo, C.; Caovilla, H.H.; Ganança, F.F. A systematic review about the effects of the vestibular rehabilitation in middle-age and older adults. Rev. Bras. Fisioter. 2010, 14, 361-371. [CrossRef]

43. Micarelli, A.; Viziano, A.; Augimeri, I.; Micarelli, D.; Alessandrini, M. Three-dimensional head-mounted gaming task procedure maximizes effects of vestibular rehabilitation in unilateral vestibular hypofunction: A randomized controlled pilot trial. Int. J. Rehabil. Res. 2017, 40, 325-332. [CrossRef]

44. Gatica-Rojas, V.; Méndez-Rebolledo, G. Virtual reality interface devices in the reorganization of neural networks in the brain of patients with neurological diseases. Neural Regen. Res. 2014, 9, 888. [CrossRef] [PubMed]

45. Pereira, E.M.; Rueda, F.M.; Diego, I.A.; De La Cuerda, R.C.; De Mauro, A.; Page, J.M. Use of virtual reality systems as proprioception method in cerebral palsy: Clinical practice guideline. Neurología 2014, 29, 550-559.

46. Veličković, P.; Milovanović, M. Improvement of the Interaction Model Aimed to Reduce the Negative Effects of Cybersickness in VR Rehab Applications. Sensors 2021, 21, 321. [CrossRef] [PubMed]

47. Davis, S.; Nesbitt, K.; Nalivaiko, E. A systematic review of cybersickness. In Proceedings of the 2014 Conference on Interactive Entertainment, Newcastle, Australia, 2-3 December 2014; pp. 1-9.

48. Bisdorff, A.R.; Staab, J.P.; Newman-Toker, D.E. Overview of the international classification of vestibular disorders. Neurol. Clin. 2015, 33, 541-550. [CrossRef]

49. Riccelli, R.; Passamonti, L.; Toschi, N.; Nigro, S.; Chiarella, G.; Petrolo, C.; Lacquaniti, F.; Staab, J.P.; Indovina, I. Altered insular and occipital responses to simulated vertical self-motion in patients with persistent postural-perceptual dizziness. Front. Neurol. 2017, 8, 529. [CrossRef] [PubMed]

50. Passamonti, L.; Riccelli, R.; Lacquaniti, F.; Staab, J.P.; Indovina, I. Brain responses to virtual reality visual motion stimulation are affected by neurotic personality traits in patients with persistent postural-perceptual dizziness. J. Vestib. Res. 2018, 28, 369-378. [CrossRef] [PubMed]

51. Aharoni, M.M.; Lubetzky, A.V.; Wang, Z.; Goldman, M.; Krasovsky, T. A Virtual Reality Four-Square Step Test for Quantifying Dynamic Balance Performance in People with Persistent Postural Perceptual Dizziness. In Proceedings of the 2019 International Conference on Virtual Rehabilitation (ICVR), Tel Aviv, Israel, 21-24 July 2019; pp. 1-6. 
52. Breinbauer Krebs, H.; Contreras, M.D.; Lira, J.P.; Guevara, C.; Castillo, L.; Ruedlinger, K.; Muñoz Candia, D.; Délano Reyes, P. Spatial navigation is distinctively impaired in persistent postural perceptual dizziness. Front. Neurol. 2020, 10, 1361. [CrossRef]

53. Aharoni, M.M.; Lubetzky, A.V.; Arie, L.; Krasovsky, T. Factors associated with dynamic balance in people with Persistent Postural Perceptual Dizziness (PPPD): A cross-sectional study using a virtual-reality Four Square Step Test. J. Neuroeng. Rehabil. 2021, 18, 1-12. [CrossRef]

54. Hilty, D.M.; Randhawa, K.; Maheu, M.M.; McKean, A.J.; Pantera, R.; Mishkind, M.C.; Rizzo, A. A Review of Telepresence, Virtual Reality, and Augmented Reality Applied to Clinical Care. J. Technol. Behav. Sci. 2020, 5, 178-205. [CrossRef]

55. Moro, C.; Štromberga, Z.; Raikos, A.; Stirling, A. The effectiveness of virtual and augmented reality in health sciences and medical anatomy. Anat. Sci. Educ. 2017, 10, 549-559. [CrossRef]

56. Moro, C.; Štromberga, Z.; Stirling, A. Virtualisation devices for student learning: Comparison between desktop-based (Oculus Rift) and mobile-based (Gear VR) virtual reality in medical and health science education. Australas. J. Educ. Technol. 2017, 33. [CrossRef]

57. Zaidi, S.F.M.; Male, T. Experimenting novel virtual-reality immersion strategy to alleviate cybersickness. In Proceedings of the 24th ACM Symposium on Virtual Reality Software and Technology, Tokyo, Japan, 28 November-1 December 2018; pp. 1-2.

58. Lessick, S.; Kraft, M. Facing reality: The growth of virtual reality and health sciences libraries. J. Med. Libr. Assoc. 2017, 105, 407-417. [CrossRef] [PubMed]

59. Zaidi, S.F.M.; Beilby, P.J.; Grimley, P.M. Toward Effective Virtual Reality Intervention Development Planning for People with Persistent Postural-Perceptual Dizziness. In Proceedings of the 25th ACM Symposium on Virtual Reality Software and Technology, Parramatta, Australia, 12-15 November 2019; pp. 1-2.

60. Petrosoniak, A.; Hicks, C.; Barratt, L.; Gascon, D.; Kokoski, C.; Campbell, D.; White, K.; Bandiera, G.; Lum-Kwong, M.M.; Nemoy, L.; et al. Design thinking-informed simulation: An innovative framework to test, evaluate, and modify new clinical infrastructure. Simul. Healthc. 2020, 15, 205-213. [CrossRef] [PubMed]

61. Zaidi, S.F.M.; Moore, C.; Khanna, H. Towards integration of user-centered designed tutorials for better virtual reality immersion In Proceedings of the 2nd International Conference on Image and Graphics Processing, Singapore, 23-25 February 2019; pp. 140-144.

62. Zaidi, S.F.M.; Duthie, C.; Carr, E.; Maksoud, S.H.A.E. Conceptual framework for the usability evaluation of gamified virtual reality environment for non-gamers. In Proceedings of the 16th ACM SIGGRAPH International Conference on Virtual-Reality Continuum and its Applications in Industry, Tokyo, Japan, 2-3 December 2018; pp. 1-4.

63. Coelho, L.P.; Queirós, R.; Reis, S.S. Emerging Advancements for Virtual and Augmented Reality in Healthcare. IGI Glob. 2022. [CrossRef]

64. Brightman, J. HTC Vive Is Flooding the Market While Oculus 'Took a Significant Step Forward in 2019'. GameDaily.biz, 2020. Available online: https:/ / gamedaily.biz/article/1588/htc-vive-is-flooding-the-market-while-oculus-took-a-significant-stepforward-in-2019 (accesssed on 11 December 2021).

65. GEFORCE RTX FOR VIRTUAL REALITY—Great VR Requires a Great GPU. nvidia. Available online: https://www.nvidia.com/ en-au/geforce/technologies/vr/ (accesssed on 23 December 2021).

66. Logical Increments PC Buying Guide, Logical Increments. Available online: https://www.logicalincrements.com/articles/vrguide (accesssed on 11 December 2021). 